\title{
Microplastic fiber and drought effects on plants and soil are only slightly modified by arbuscular mycorrhizal fungi
}

\author{
Anika Lehmann ${ }^{1,2,{ }^{*},}$, Eva F. Leifheit ${ }^{1,2,+}$, Linshan Feng ${ }^{1}$, Joana Bergmann ${ }^{1,2,3}$, Anja Wulf ${ }^{1}$, Matthias C. Rillig ${ }^{1,2}$ \\ 1 Freie Universität Berlin, Institut für Biologie, 14195 Berlin, Germany \\ 2 Berlin-Brandenburg Institute of Advanced Biodiversity Research, 14195 Berlin, Germany \\ 3 Leibniz Centre for Agricultural Landscape Research (ZALF), 15374 Müncheberg, Germany
}

\section{H I G H L I G H T S}

- Polyester fibers increased aboveground biomass.

- Under drought conditions the AM-fungalonly treatment had the highest biomass.

- Colonization with AM fungi increased under microfiber addition.

- The mean weight diameter of soil aggregates decreased under microplastic contamination and drought stress, respectively.

- Under drought conditions AM fungi increased litter decomposition.

\section{ARTICLE INFO}

Article history:

Received June 8, 2020

Revised August 2, 2020

Accepted August 7, 2020

\section{Keywords:}

Arbuscular mycorrhizal fungi

Microplastic

Soil aggregation

Organic matter decomposition

Drought

Root traits

\section{GRAPHICAL ABSTRACT}

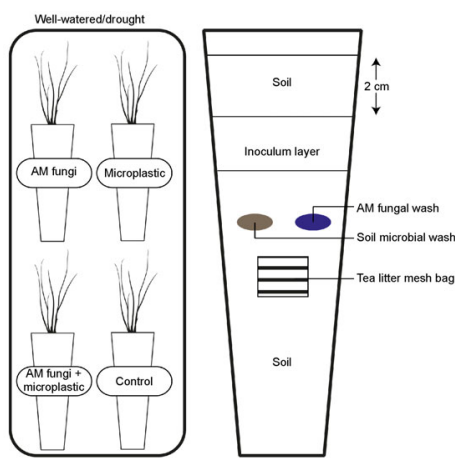

A B S TR A C T

Microplastics are increasingly recognized as a factor of global change. By altering soil inherent properties and processes, ripple-on effects on plants and their symbionts can be expected. Additionally, interactions with other factors of global change, such as drought, can influence the effect of microplastics. We designed a greenhouse study to examine effects of polyester microfibers, arbuscular mycorrhizal (AM) fungi and drought on plant, microbial and soil responses. We found that polyester microfibers increased the aboveground biomass of Allium cepa under well-watered and drought conditions, but under drought conditions the AM fungal-only treatment reached the highest biomass. Colonization with AM fungi increased under microfiber contamination, however, plant biomass did not increase when both AM fungi and fibers were present. The mean weight diameter of soil aggregates increased with AM fungal inoculation overall but decreased when the system was contaminated with microfibers or drought stressed. Our study adds additional support to the mounting evidence that microplastic fibers in soil can affect the plant-soil system by promoting plant growth, and favoring key root symbionts, AM fungi. Although soil aggregation is usually positively influenced by plant roots and AM fungi, and microplastic promotes both, our results show that plastic still had a negative effect on soil aggregates. Even though there are concerns that microplastic might interact with other factors of global change, our study revealed no such effect for drought.

(C) The Author(s) 2020. This article is published with open access at link.springer.com and journal.hep.com.cn

\section{* Corresponding author}

E-mail address: lehmann.anika@googlemail.com (A. Lehmann)

†These authors contributed equally to this work.

\section{Introduction}

Microplastic is becoming increasingly recognized as a factor of global change (Rillig, 2012; Machado et al., 2018a; Ng et al., 2018), owing to the fact that these materials are ubiquitously found in various environmental compartments 
(Cole et al., 2011; Eerkes-Medrano et al., 2015; Machado et al., 2018a; Bergmann et al., 2019) and can potentially affect ecosystems and biodiversity. The research focus has recently shifted to include terrestrial ecosystems and the soil, but research in marine environments is much more advanced, since it started roughly a decade earlier (Thompson et al., 2009).

Microplastics are a complex group of compounds encompassing a wide range of properties in terms of sizes, shapes, chemistries, states of weathering, and additives, both intentional and unintentional (Wagner et al., 2014). They are either produced already as micro-sized particles $(<5 \mathrm{~mm}$ ), the socalled primary microplastics, or reach this size through fragmenting from larger pieces, the secondary microplastics (Hartmann et al., 2019). For agricultural soils, sewage sludge is an important source of primary and secondary microplastic. Wastewater treatment plants filter out solid particles originating from roads and households, such as tire abrasion particles and fibers from washing synthetic clothes. The filtered particles are retained in the sewage sludge, which is used as fertilizer in large quantities (Nizzetto et al., 2016; van den Berg et al., 2020).

Effects of microplastics on the environment are manifold. In terrestrial systems, these include changes in basic soil parameters, including bulk density, soil structure and water holding capacity (Machado et al., 2018b). By altering the soil inherent properties and processes, microplastic-induced ripple-on effects on soil biota and plants can be expected (Rillig et al., 2019a). There is evidence that plant performance is affected by microplastics, often positively (Machado et al., 2018b), but also negatively (Qi et al., 2018; van den Berg et al., 2020), likely as a function of the identity and traits of the material added.

There are several unknowns that prevent us from making reliable predictions for how plants will respond to microplastics. Beside the microplastic features, these include (i) that we do not know how any such responses depend on key plant mutualists, including arbuscular mycorrhizal (AM) fungi; (ii) that microplastic might interact with other factors of global change, such as drought; and (iii) how these interrelated factors modulate plant, microbial and soil responses. To target these limitations in our knowledge, we designed the current study.

Previous work (Machado et al., 2019) has revealed that plant performance can be positively affected by microplastic presence in the soil, most strikingly by the presence of microplastic fibers, likely as a consequence of their linear shape (Rillig et al., 2019b). In that experiment, microplastic fibers also elicited a marked increase in root colonization by AM fungi, concomitantly to increased plant biomass. This raises the possibility that $A M$ fungi helped the plant respond positively to microplastic fiber contamination of the soil, likely by supporting the plant in taking up nutrients. However, this remains to be tested in other plant species, and verified by including $\mathrm{AM}$ fungi as a factor in a study. Hence, we here include both microplastic fibers and AM fungi as factors in a factorial experiment.

Our knowledge about any interactions of microplastic with other drivers of global change is highly limited. Rillig et al. (2019c) have shown that increased numbers of global change drivers can lead to effects that are difficult to predict from knowing single-factor effects, and that "ecological surprises" can occur in soil properties when considering higher-order interactions. Liang et al. (2019) found that microplastic can interact in complex ways with temperature in producing different rates of soil aggregation in different soil fungal isolates. Increased prevalence of drought is another key driver expected to increase in the future (Marvel et al., 2019), and thus we here included drought as an additional factor in this study. Furthermore, microplastic-induced soil responses, including water holding capacity and bulk density, can be expected to modify drought-related effects.

Recent studies demonstrated that microplastics modulate soil structural responses with generally negative impacts for fibrous shapes (e.g., Machado et al., 2018b; Zhang et al., 2019; Lehmann et al., 2020). Individual studies could verify these findings for both soil aggregate formation and stabilization, while a recent meta-analysis supported this pattern only for the stabilization of soil aggregates (Lehmann et al., 2020). Soil aggregates and their associated soil pore network are the building blocks of the soil matrix determining soil inherent processes, including carbon cycling, and enable a high microbial biodiversity. But these aggregates are vulnerable to microplastics: Observations of microfiber contaminated soil revealed that the material can be incorporated into aggregates, likely introducing fracture points or pathways for the entry of water into aggregates.

We know relatively little about ecosystem responses to microplastics (Rillig and Lehmann, 2020); and one key process with large unknowns is decomposition. Decomposition rates determine organic matter turnover and thus nutrient availability, carbon loss and carbon storage. This important process is not only important for ecosystem functioning but also relates to soil carbon cycling on larger scales and to earth system feedbacks. Our knowledge about how this process is affected by microplastic is highly limited, and thus inferences on plastic-induced effects and potential underlying mechanisms are not possible. One issue with such work derives from the nature of microplastic itself, since it is a source of carbon not distinguishable by standard methods from any other organic molecule containing carbon (Rillig, 2018). Thus, organic matter carbon dynamics cannot be reliably investigated for their response to microplastic addition without disentangling these sources of carbon. The available and suitable data suggest mainly neutral effects of microplastics on the decomposition of organic material that was specifically added (e.g., cellulose strips or leaf litter (e.g., Rillig et al., 2019c; Lehmann et al., 2020)).

These findings on soil structure and organic matter decomposition responses resulted from experiments without 
a growing plant. Thus, we intended to investigate these responses and their modulation in the presence of a plant AM fungal symbiosis and the integrated impact of the major global change factor drought. For this, we designed a greenhouse experiment in which to study the effects of microplastic on soil parameters and plant performance, as modified by AM fungal presence and drought. We hypothesized that AM fungi will help plants respond positively to microplastic, and will help buffer against the effects of drought. As drought affects plant growth negatively, while microplastic often has positive effects, we further hypothesized that microplastics, together with AM fungi, will ameliorate effects of drought. Finally, we hypothesize that the positive AM fungal induced plant responses have positive ripple-on effects on soil inherent processes, such as soil structure and organic matter decomposition.

\section{Materials and methods}

To test the effects of drought and microplastic on plant and AM fungal interactions, we set up a greenhouse experiment with a $2 \times 2 \times 2$ fully factorial design. The three treatments were AM fungal inoculation (yes/no), microfiber addition (yes/no) and drought (well-watered/drought) each replicated 10 times; yielding 80 experimental units.

\subsection{Experimental setup}

We set up the experiment in a climate-controlled greenhouse with a daylight period set to $12 \mathrm{~h}, 50 \mathrm{klx}$ lighting, and a temperature regime at $22 / 18^{\circ} \mathrm{C}$ day/night with relative humidity of $\sim 40 \%$. The experiment was conducted during June/July 2019.

\subsubsection{Growth substrate and microfibers}

As growth substrate, we used a local soil with sandy loam texture (Albic Luvisol following FAO classification; $74 \%$ sand, $18 \%$ silt, $8 \%$ clay), $6.9 \mathrm{mg} / 100 \mathrm{~g} \mathrm{P}$ (calcium-acetate-lactate), $5.0 \mathrm{mg} / 100 \mathrm{~g} \mathrm{~K}$ (calcium-acetate-lactate), $0.12 \%$ total $\mathrm{N}$ and $1.87 \%$ total $\mathrm{C}$ content and a soil pH of 7.1 (Rillig et al., 2010). The soil was sieved to $<2 \mathrm{~mm}$ and mixed with sand $(<2 \mathrm{~mm}$ fraction) at a ratio of $1: 1$, to reduce organic matter concentration and hence nutrient bio-availability. For microplastic contamination, we manually cut polyester microfibers (commercial Paraloc rope, Mamutec, Switzerland, product number: 0025-00080-01-0, white, diameter of $30 \mu \mathrm{m}$ ) to generate secondary microfiber fragments (mean length: $1.70, \mathrm{sd}=$ $0.92, n=130$; Fig.S1). Many rope products of this manufacturer contain UV-Stabilizer as additives. The prepared microfibers were manually incorporated into the soil-sand mixture at a concentration of $0.4 \%$ (w:w) following previous studies (Machado et al., 2018b; Machado et al., 2019) that reported strongest microplastic-induced effects for this concentration. The control soil without microplastic was mixed just as thoroughly for the same amount of time to apply comparable disturbance. The prepared soil-sand mixtures with and without microfibers were steam sterilized at $100^{\circ} \mathrm{C}$ twice to inactivate soil microbes, especially propagules of $A M$ fungal species.

\subsubsection{AM fungal inoculum and microbial community}

To introduce an AM fungal treatment, we chose a commercial inoculum (INOQ Agri, INOQ GmbH, Germany) including three arbuscular mycorrhizal species: Rhizoglomus irregulare (Blaszk., Wubet, Renker \& Buscot) C. Walker \& A. Schüßler comb. nov., Funneliformis mosseae (T.H. Nicolson \& Gerd.) C. Walker \& A. Schüßler comb. nov. and Funneliformis caledonium (T.H. Nicolson \& Gers.) C. Walker \& A. Schüßler comb. nov. (Schussler and Walker, 2010), on vermiculite as carrier material (diameter: 1-2 mm). To control for potential confounding effects by the carrier material (e.g., nutrient loading, structure), we prepared an autoclaved (two-times $30 \mathrm{~min}$ at $121^{\circ} \mathrm{C}$ in dry cycle) portion of the inoculum for the AM fungal controls. Additionally, it was necessary to control for the nonAM fungal microbial community introduced via the commercial inoculum. We prepared an "inoculum wash." For this, $100 \mathrm{~mL}$ INOQ Agri were solved in $350 \mathrm{~mL}$ distilled water and thoroughly mixed. After 5 min of rest, the liquid was decanted over a pre-sterilized (70\% ethanol, for $5 \mathrm{~min}$ ) $20 \mu \mathrm{m}$ mesh sieve.

Since the soil-sand mixture was steam sterilized, we reintroduced a microbial, non-AM fungal community to the soil of our test system via a "microbial wash." For this, $2 \mathrm{~kg}$ of fresh, unsterile soil-sand mixture from the same soil as used for the experiment, were suspended in $2 \mathrm{~L}$ of distilled water. The same procedure as for the "inoculum wash" was applied.

\subsubsection{Litter bags}

To investigate the consequences of microfiber contamination on microbial decomposition, we created miniature tea bags (Keuskamp et al., 2013). A $30 \mu \mathrm{m}$ nylon mesh (Sefar Nitex) was cut into $2.5 \mathrm{~cm} \times 3 \mathrm{~cm}$ rectangles, folded and both $1.5 \mathrm{~cm}$ long sides closed via an impulse sealer (Mercier Corporation, product no. 127174). The bags were filled with $300 \mathrm{mg}$ green tea (Lipton green tea, Sencha Exclusive Selection), sealed and autoclaved $\left(121^{\circ} \mathrm{C}\right.$ for $20 \mathrm{~min}$ in dry cycle) before they were introduced to the test system.

\subsubsection{Experimental setup}

The experimental system (Fig. S2) was established in presterilized, white polypropylene pots (Ray Leach Cone-tainers, Stuewe and Sons Inc.). The bottom of the pots was lined with a black mesh (Premium Weedmac, DuPont Plantex, product no. P467-12014) and covered with $40 \mathrm{~g}$ autoclaved sand. Pots were loaded with $150 \mathrm{~g}$ of fiber contaminated or fiber-free control soil in which we inserted the tea bags and introduced the "inoculum wash" (1 $\mathrm{mL})$ (to equilibrate the microbial community from the AMF-inoculum) and "microbial wash" (2 $\mathrm{mL}$ ) (to equilibrate the microbial community from the soil). We did not artificially compress the soil. The AM fungal inoculum was added on top as a band sandwiched between 
two layers of soil-sand-mix to the pots with a concentration of $10 \%$ (w:w; following the producer guideline). The position of the inoculum band was chosen to allow early colonization of seedlings by AM fungi. For the AM fungal controls, we added the autoclaved inoculum portion. Established test systems were covered with a $5 \mathrm{~mm}$ layer of sterile sand and were watered to $70 \%$ water holding capacity with microplastic free distilled water (Mintenig et al., 2019). Pots were watered from above. The amount of water was determined by weight loss and refilled to reach pre-determined weight of the system at $70 \%$ water holding capacity.

After equilibration overnight, we introduced seeds of Allium cepa (variety "Kaigaro," Albert Treppens \& Co Samen GmbH, EG Pflanzenpass Nr.: DE-BE1-29005 RP 25003 253840), a mycorrhiza-responsive plant species with large diameter fine roots. Three surface sterilized ( $7 \%$ sodium hydrochloride for 3 min) seeds of Allium cepa were placed in the soil of each pot and seedlings thinned to one upon emergence.

\subsubsection{Drought treatment}

We initiated the drought treatment on day 30 of the experiment by allowing the water holding capacity to drop to $30 \%$ (de Vries et al., 2016). This is a commonly applied drought level in ecological studies. Plants were watered three-times a week to maintain targeted soil moisture levels (for drought and wellwatered conditions). The experiment then lasted for another 20 days. Pots were re-distributed randomly every week until harvest.

\subsubsection{Harvest}

Watering of pots was stopped four days before harvest to reduce the disturbance effect of the harvest procedure on the soil structure. Soil and whole plants were carefully extracted from the pots and spread in white trays to collect all root fragments and the tea bag. Subsequently, the surface soil layer, the inoculation band and the sand in the pot bottom were discarded. Plant biomass was separated into an above(leaves and bulb) and below-ground (roots) portion. Plant roots were visually inspected to identify fine roots (white color, orders 1-3) which were cut underneath the bulb at the center of the pot. A fraction of fine roots was collected and stored in distilled water overnight at $4^{\circ} \mathrm{C}$ until further processing within less than a week. The remaining roots including those growing into the sand and mesh at the pot bottom and/or touching the pot wall were cut off and pooled. Soil samples, tea bags, aboveground biomass and pooled roots were each dried at $40^{\circ} \mathrm{C}$ and stored until further usage.

\subsection{Measurements}

\subsubsection{Root traits}

We measured root traits on the fresh fine roots stored for a maximum of 7 days after washing in water at $4^{\circ} \mathrm{C}$. Absorptive fine roots were defined as living roots of first to third order (McCormack et al., 2015). The samples were spread in $50 \mathrm{~mL}$ distilled water on PVC trays and scanned (Epson Perfection Scan V800, 8-bit grayscale, $800 \mathrm{dpi}$ ). Scanned root samples were dried at $40^{\circ} \mathrm{C}$ before determining dry biomass for the calculation of root traits. Root scans were analyzed with WinRhizo (WinRHIZO Pro v. 2007d, Regent Instrument Inc., Quebec, Canada). We defined diameter size classes of $0.1 \mathrm{~mm}$ to calculate the root volume (Rose, 2017) and to determine the maximum root diameter which was below $2 \mathrm{~mm}$ in all samples. Analysis settings were chosen for high precision and exclusion of debris $\left(0.0005 \mathrm{~mm}^{2}\right)$. Scan data and dried fine root mass was combined to calculate the following root traits: root average diameter (in $\mathrm{mm}$ ), specific root length (SRL; $\mathrm{m} \mathrm{g}^{-1}$ ), specific root surface area (SRSA; $\mathrm{cm}^{2} \mathrm{~g}^{-1}$ ) and root tissue density (RTD; root DW per volume $\mathrm{g} \mathrm{cm}^{-3}$ )

\subsubsection{Plant biomass}

For the determination of total plant biomass production we measured aboveground and belowground dry biomass while the biomass of root samples from the scanning process was added to those of all other pooled roots for total root biomass determination.

\subsubsection{Decomposition}

To investigate the decomposition of the tea matter from the miniature tea bags, we calculated the relative mass remaining $\left(\mathrm{g} \mathrm{g}^{-1}\right)$ on a dry matter basis. Two teabags were lost during the harvest.

\subsubsection{Mycorrhizal colonization}

Percent colonization of host roots by AM fungi was measured to demonstrate the success of inoculation and to determine the proportion of different AM fungal structures. We used the magnified gridline intersect method at $200 \times$ magnification (100 intersects per sample) (McGonigle et al., 1990; Rillig et al., 1999).

\subsubsection{Soil aggregation}

We measured the size class distribution of soil aggregates, following a modified protocol by Kemper and Rosenau (1986). Soil samples were prepared by carefully passing them through a $4 \mathrm{~mm}$ sieve. Subsequently, samples were introduced to a stack of four sieves $(2,1,0.25$ and $0.1 \mathrm{~mm})$ for separation into five fractions of decreasing particle size. The sieve stack was moved vertically 14-times to ensure particle separation over the different mesh sizes while minimizing abrasion. Fraction weights were collected to calculate the mean weight diameter (in mm): MWD $=\sum_{i=1}^{n} \bar{x}_{i} w_{i}$, where $\bar{x}_{i}$ is the mean diameter of size fraction $i$ and $w_{i}$ is the proportion of total soil mass in size fraction $i$. In this formula, the soil aggregate size classes are weighted by their mean diameter. Hence, with increasing MWD the overall amount of large aggregates in a sample increases. 
We also tested the water-stability of the soil aggregates. For this, we carefully mixed the soil samples after measuring the MWD, placed $4.0 \mathrm{~g}$ of each sample on a small sieve with a mesh size of $250 \mu \mathrm{m}$. Then, the samples were capillarily rewetted with deionized water and placed in a sieving machine (Agrisearch Equipment, Eijkelkamp, Giesbeek, Netherlands). For $3 \mathrm{~min}$, samples were moved vertically in small metal cups filled with deionized water. This way, samples were separated into a water-stable and water-unstable fraction with a size $>250 \mu \mathrm{m}$. In a second step, sand particles and organic debris were extracted from the water-stable fraction. The different fractions (starting soil volume of $4.0 \mathrm{~g}$ and waterstable fraction) were corrected for the coarse matter fraction to correctly determine the percentage of water-stable aggregates (WSA):

WSA $=($ Water stable fraction - Coarse matter $) /(4 g$-coarse matter).

\subsection{Statistics}

We performed statistics in $\mathrm{R}$ ( $\mathrm{R}$ Development Core Team, 2014). We investigated the effects of our three treatments (AM fungal inoculation, microfiber addition and drought) on the various measured variables by a two-step approach. In the first step, we used the package "dabestr" (Ho et al., 2019) to generate unpaired mean differences by a bootstrapping approach (5000 iterations). This type of estimation method brings the magnitude of an effect and its precision into focus. Additionally, the information offered by the effect size and confidence interval $(\mathrm{Cl})$ is further supported by the samplingerror distribution which is plotted alongside. We used the estimation method to evaluate the treatment effects, with special focus on microplastic and AM fungi, across drought and well-watered conditions. With the second step, we supported our findings by generalized least square models in the "nlme" package (Pinheiro et al., 2018) with implemented varldDent() function to account for heterogeneity in the drought treatment. Model residuals were checked for heteroscedasticity and normal distribution. The plots were generated with the packages "dabestr" and "ggplot2" (Wickham, 2009). All data used for analyses and plotting are available in the supplementary data (https://doi.org/10.6084/m9.figshare.12732329.v1).

\section{Results}

\subsection{Plant response}

We detected positive effects on aboveground biomass production for the individual addition of AM fungi and microfibers under well-watered and drought conditions (Fig. 1, Table 1) while we found, in general, a strong negative impact for drought. The highest values for aboveground biomass were detected (i) for the application of microfibers under well-watered conditions and in the absence of AM fungi [+ $71.9 \mathrm{mg}(95 \%-\mathrm{Cl}: 41.6$ to $104.0 \mathrm{mg})$ ], and (ii) for the AM fungal treatment under drought and in the absence of microplastic [+57.1 mg $(95 \%-\mathrm{Cl}: 32.1$ to $84.8 \mathrm{mg})]$. The dual-application of both AM fungi and microfibers caused no further biomass increase, since the biomass did not exceed AM fungal- or microplastic-only levels; this pattern was consistent under well-watered and drought conditions.

There was no single factor effect present for belowground biomass (Fig. 1, Table 1). Only a marginal interaction for AM fungi and microfibers, as was detectable for aboveground biomass; i.e., in the absence of AM fungi, well-watered plants showed increased belowground biomass when the soil was contaminated with microfibers.

In general, all investigated root traits were affected by drought (Fig. 2, Table 1); i.e., specific root length and surface area decreased while the root average diameter and tissue density increased under drought conditions. Root average diameter was the only root trait affected by microfiber contamination; we detected a negative effect for microplastic treatment in the absence of AM fungi under well-watered conditions ( $-40.3 \mu \mathrm{m}$ [95\%-Cl: -66.7 to $-17.0 \mu \mathrm{m}])$ (Fig. $2 \mathrm{C}$, Table 1). AM fungal inoculation tended to decrease specific root length and specific root surface area while increasing root average diameter and root tissue density, even though this effect was not statistically supported (Fig. 2, Table 1) and only showed up in the unpaired mean differences of specific root surface area under drought conditions and microplastic absence [-204 $\mathrm{cm}^{2} \mathrm{~g}^{-1}$ (95\%-Cl: -413 to $\left.-2.04 \mathrm{~cm}^{2} \mathrm{~g}^{-1}\right)$.

\subsection{AM fungal response}

The AM fungal inoculum led to a successful colonization of the test plants (Fig. S3). We found highest colonization rates under microfiber contamination and well-watered conditions [+ 8\% (95\%-Cl: 0 to 16.5\%)] (Fig. 3, Table 2). Under the same conditions, we found an increase in arbuscule but not vesicle colonization (Fig. S4A, Table S1). Vesicle colonization was increased under microplastic presence and drought conditions (Fig. S4B).

\subsection{Soil responses}

The mean weight diameter increased with sole AM fungal inoculation but decreased when the system was only contaminated with microfibers, irrespective of the watering condition. In general, drought reduced the mean weight diameter [ $-40.5 \mu \mathrm{m}(95 \%-\mathrm{Cl}:-69.9$ to $-8.1 \mu \mathrm{m})$ ] (Fig. 4, Table 2). But the negative effect of microfibers was most pronounced under well-watered conditions [-41.3 $\mu \mathrm{m}$ ( 95\%Cl: -77.2 to $-9.2 \mu \mathrm{m})$ ]. We did not find a clear response for the water-stability of soil aggregates (Fig. S5, Table S2).

For organic matter decomposition, we only detected a clear effect for the AM fungal inoculum; under drought conditions and in the presence of AM fungi, we found the highest mass loss of tea litter [6.9 mg (95\%-Cl: -2.3 to $16.3 \mathrm{mg})$ ] (Fig. 4). For microfibers, we detected no effects on organic matter loss, irrespective of the watering condition. 

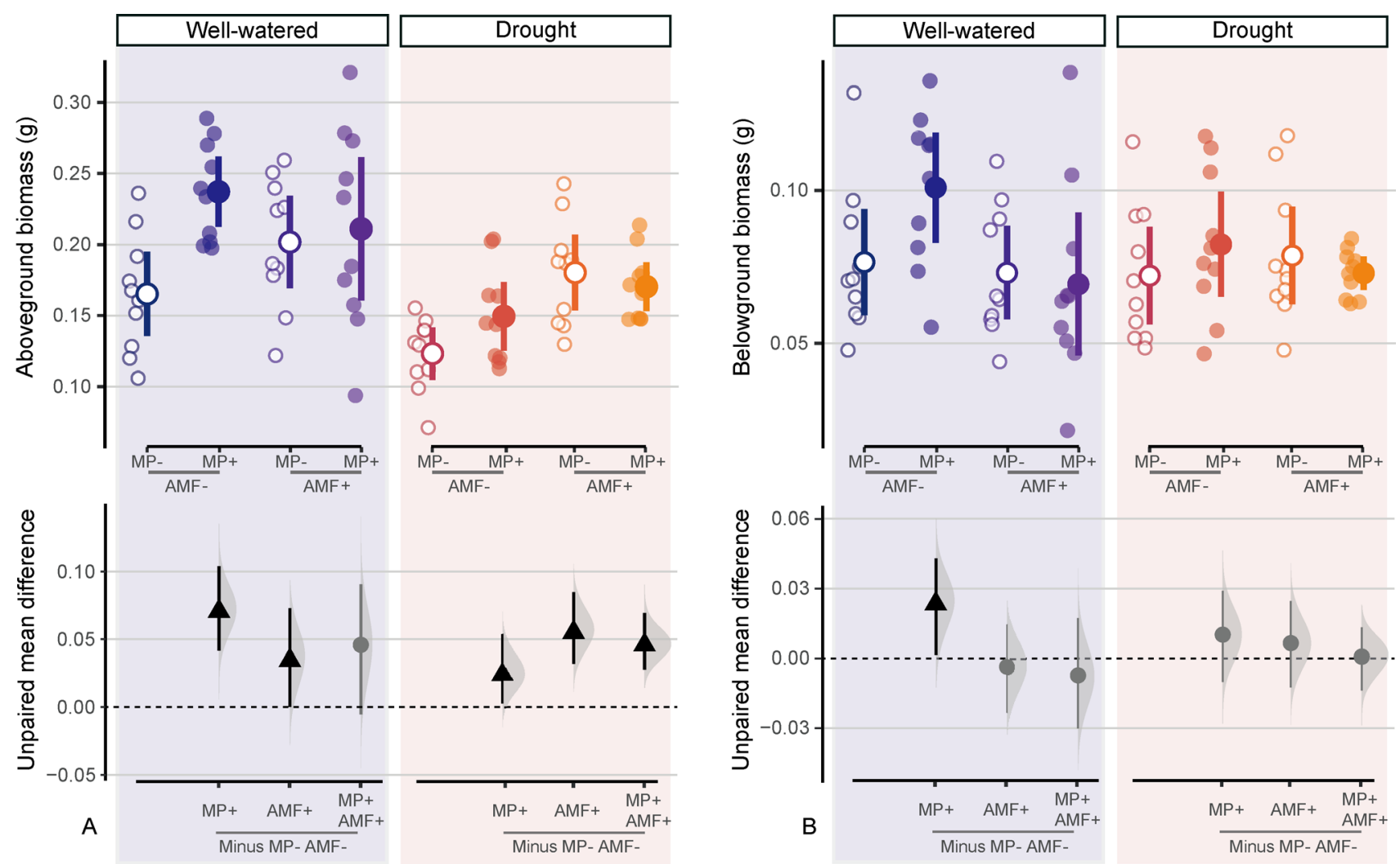

Fig. 1 Biomass responses to application of microfibers, AM fungi and drought. Raw data distributions for aboveground (A) and belowground biomass (B) in $\mathrm{g}$ are presented as swarm plots (first row). Data distributions are aligned with corresponding mean and standard deviation ( $n=10$ for each group). Blueish colors represent well-watered and reddish drought conditions. Empty circles depict absence and filled circles presence of microfiber contamination. The multi-group estimation plots (second row) depict the unpaired mean differences of the microplastic- and AM fungal-only and microplastic-AM fungal combination under wellwatered and drought scenario. Samples without AM fungi and microplastic were used as control group for well-watered and drought conditions, separately. Circles and triangles represent the effect size mean (unpaired mean; effect magnitude) and the vertical lines the corresponding confidence intervals (effect precision). The sampling error distribution is presented as a gray curve. Positive (arrow head up) or negative (arrow head down) effect sizes and corresponding Cls of treatment compared to control group are depicted in black while neutral effects (circle) are colored in gray; neutral effects occur when the Cls overlap the dashed zero line (line of no effect). Model outcomes of raw data analyses are presented in Table 1.

Table 1 Outcomes of the generalized least square models for the investigated plant traits aboveground biomass (AGB in $\mathrm{g}, n=80)$, belowground biomass (BGB in $\mathrm{g}, n=80$ ), specific root length ( $\mathrm{SRL}$ in $\mathrm{g}^{-1}, n=80$ ), specific root surface (SRS in $\mathrm{cm}^{2} \mathrm{~g}^{-1}, n=80$ ), root average diameter (RAD in $\mathrm{mm}, n=80$ ) and root tissue density (RTD in $\mathrm{g} \mathrm{cm}^{-3}, n=80$ ) for the treatments (AMF = arbuscular mycorrhizal fungi, MP = microplastic, $\mathrm{D}=$ drought).

\begin{tabular}{|c|c|c|c|c|c|c|c|c|c|c|c|c|c|}
\hline \multirow[t]{2}{*}{ Treatments } & \multirow[t]{2}{*}{$\mathrm{df}$} & \multicolumn{2}{|c|}{ AGB } & \multicolumn{2}{|c|}{ BGB } & \multicolumn{2}{|c|}{ SRL } & \multicolumn{2}{|c|}{ SRSA } & \multicolumn{2}{|c|}{ RAD } & \multicolumn{2}{|c|}{ RTD } \\
\hline & & $F$ & $p$ & $F$ & $p$ & $F$ & $p$ & $F$ & $p$ & $F$ & $p$ & $F$ & $p$ \\
\hline MF & 1,72 & 12.9112 & 0.0006 & 2.153 & 0.1466 & 1.8041 & 0.1834 & 1.7507 & 0.19 & 1.253 & 0.2668 & 0.005 & 0.9433 \\
\hline MP & 1,72 & 4.2479 & 0.0429 & 1.0704 & 0.3043 & 3.2223 & 0.0768 & 1.5859 & 0.212 & 10.279 & 0.002 & 0.401 & 0.5285 \\
\hline D & 1,72 & 26.767 & $<0.0001$ & 0.4314 & 0.5134 & 16.1075 & 0.0001 & 16.2159 & 0.0001 & 10.455 & 0.0018 & 27.772 & $<0.0001$ \\
\hline MF: MP & 1,72 & 6.8948 & 0.0106 & 4.1144 & 0.0462 & 0.7845 & 0.3787 & 2.5199 & 0.1168 & 0.763 & 0.3854 & 6.466 & 0.0131 \\
\hline$M F: D$ & 1,72 & 3.3157 & 0.0728 & 2.3733 & 0.1278 & 0.7597 & 0.3863 & 1.7323 & 0.1923 & 0.249 & 0.6191 & 2.85 & 0.0957 \\
\hline$M P: D$ & 1,72 & 3.0502 & 0.085 & 0.597 & 0.4422 & 1.1584 & 0.2854 & 0.8906 & 0.3485 & 0.21 & 0.6483 & 0.038 & 0.8455 \\
\hline AMF:MP:D & 1,72 & 0.5094 & 0.4777 & 0.3322 & 0.5661 & 0.0028 & 0.9582 & 0.0218 & 0.8831 & 0.793 & 0.3763 & 0.046 & 0.83 \\
\hline
\end{tabular}

$p<0.05$ was considered significant and marked in bold. Degrees of freedom (df), $F$ - and $p$-value for each variable are presented. 

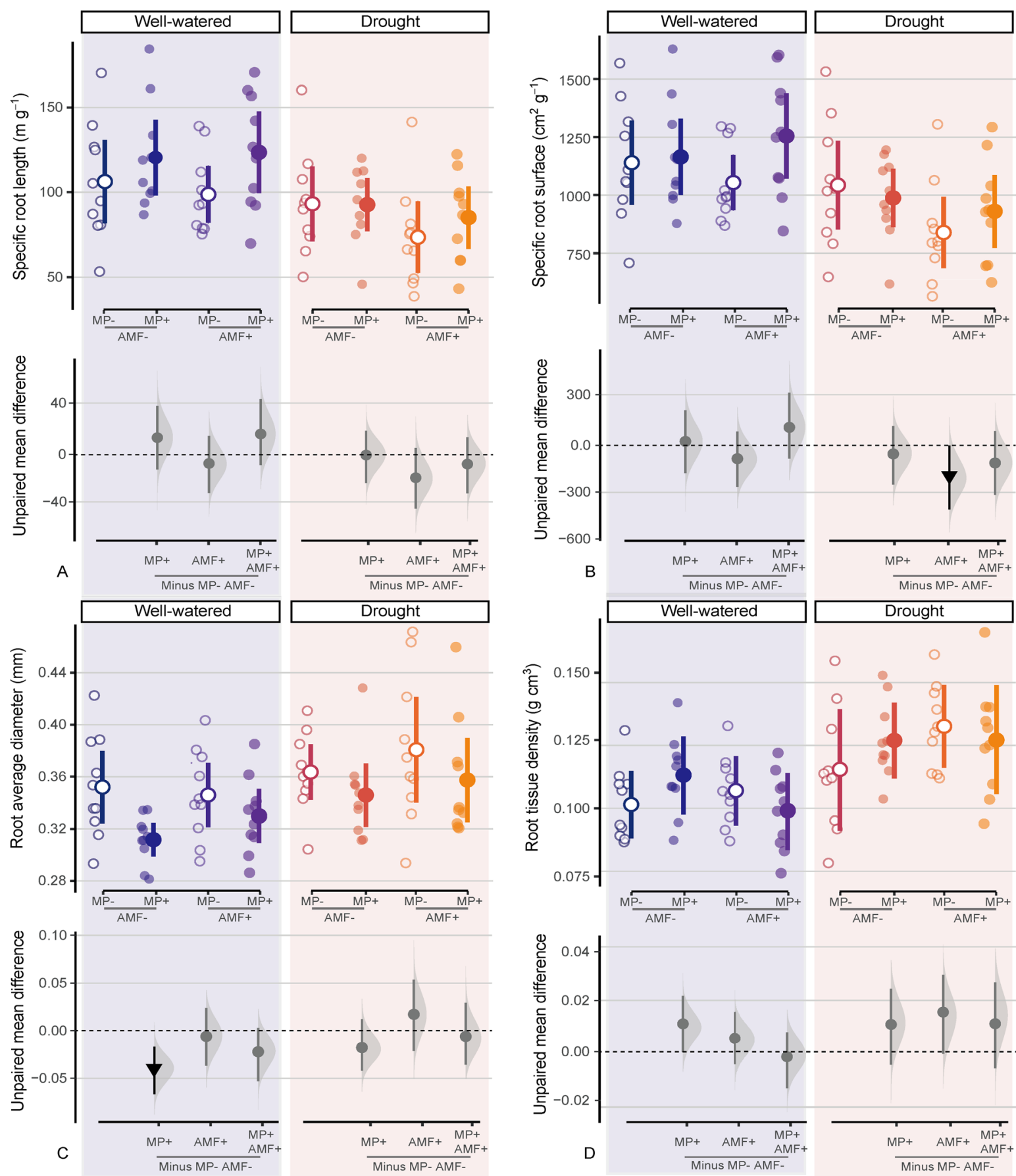

Fig. 2 Root trait responses to application of microfibers, AM fungi and drought. Raw data distributions for specific root length in $\mathrm{m} \mathrm{g}^{-1}(\mathrm{~A})$, specific root surface in $\mathrm{cm}^{2} \mathrm{~g}^{-1}(\mathrm{~B})$, root average diameter in $\mathrm{mm}(\mathrm{C})$ and root tissue density in $\mathrm{g} \mathrm{cm}^{-3}(\mathrm{D})$ are presented as swarm plots (first row). Data distributions are aligned with corresponding mean and standard deviation ( $n=10$ for each group). Blueish colors represent well-watered and reddish drought conditions. Empty circles depict absence and filled circles presence of microfiber contamination. The multi-group estimation plots (second row) depict the unpaired mean differences of the microplasticand AM fungal-only and microplastic-AM fungal combination under well-watered and drought scenario. Samples without AM fungi and microplastic were used as control group for well-watered and drought conditions, separately. Circles and triangles represent the effect size mean (unpaired mean; effect magnitude) and the vertical lines the corresponding confidence intervals (effect precision). The sampling error distribution is presented as a gray curve. Positive (arrow head up) or negative (arrow head down) effect sizes and corresponding Cls of treatment compared to control group are depicted in black while neutral effects (circle) are colored in gray; neutral effects occur when the Cls overlap the dashed zero line (line of no effect). Model outcomes of raw data analyses are presented in Table 1. 


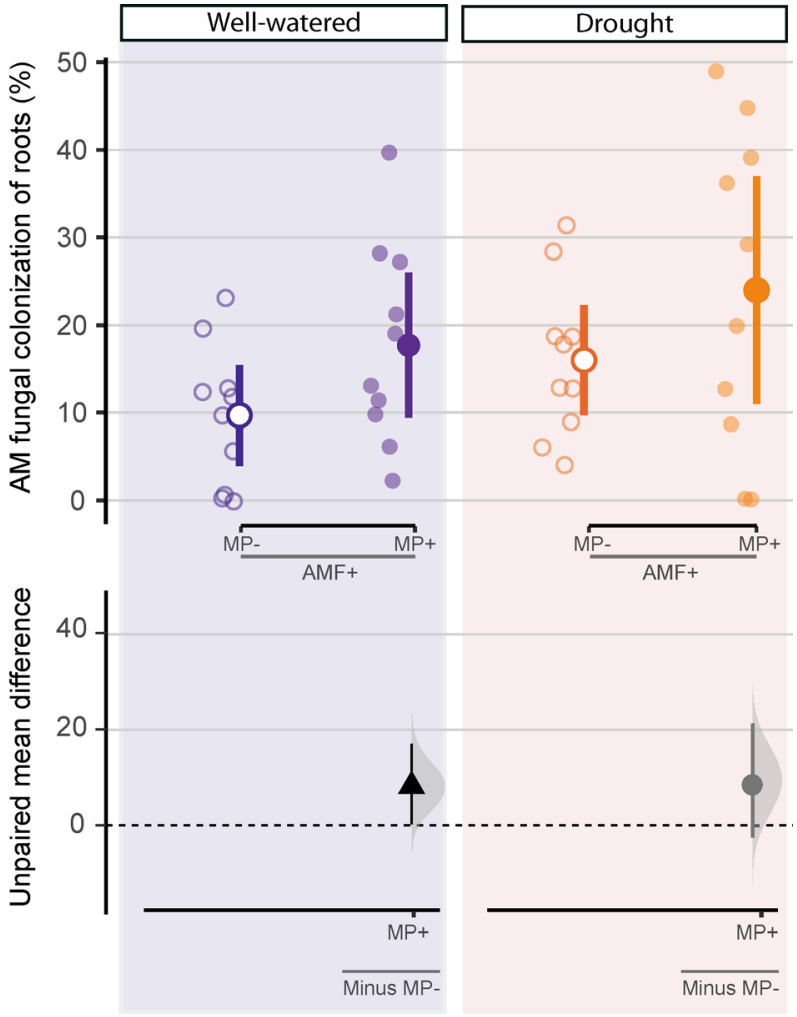

Fig. 3 Percentage colonization of onion roots by AM fungal inoculum responding to application of microfibers, AM fungi and drought. Data distributions are aligned with corresponding mean and standard deviation $(n=10$ for each group). Blueish colors represent well-watered and reddish drought conditions. Empty circles depict absence and filled circles presence of microfiber contamination. The multi-group estimation plots (second row) depict the unpaired mean differences of the microplastic- and AM fungal-only and microplastic-AM fungal combination under well-watered and drought scenario. Samples without AM fungi and microplastic were used as control group for well-watered and drought conditions, separately. Circles and triangles represent the effect size mean (unpaired mean; effect magnitude) and the vertical lines the corresponding confidence intervals (effect precision). The sampling error distribution is presented as a gray curve. Positive (arrow head up) or negative (arrow head down) effect sizes and corresponding $\mathrm{Cls}$ of treatment compared to control group are depicted in black while neutral effects (circle) are colored in gray; neutral effects occur when the Cls overlap the dashed zero line (line of no effect). Model outcomes of raw data analyses are presented in Table 2.

\section{Discussion}

\subsection{Plant response}

Polyester microfiber contamination resulted in improved growth of the aboveground and belowground portion
(Fig. 1). This effect is well known (e.g., Machado et al., 2019) and mainly mediated by altered soil physical parameters. Microfibers lower the bulk density of the soil which can improve the water holding capacity of the soil (Machado et al., $2018 \mathrm{~b}$ ) and which is typically related to a better soil aeration (Hakansson and Lipiec, 2000; Niu et al., 2012). Such altered soil parameters facilitate root biomass production and thus improve the nutrient and water supply of the plant causing higher aboveground and total biomass production. We found only limited responses in root traits to polyester microfiber contamination with a decrease in root average diameter being the only statistically supported effect (Fig. 2). This finding is supported by results of a recent study by Machado et al. (2019). The microfiber-induced reduction in bulk density enhances the rootability of the soil. In a less compact soil less penetration resistance has to be overcome by the root system and thus plant roots decrease in diameter (Materechera et al., 1992). The strongest and most uniform effect observed for fine root traits was a general shift from thin high specific root length roots to thicker and denser low specific root length roots under drought conditions. This is consistent with previous findings (Fort et al., 2015; Larson and Funk, 2016) and might be a mechanism for better soil penetration and greater root longevity (McCormack et al., 2012).

For AM fungi, we found a positive impact on aboveground biomass. Depending on the context, AM fungi are known for their biomass promoting potential (e.g., Hoeksema et al., 2010; Smith et al., 2010). This is especially true under drought conditions (Jayne and Quigley, 2014; Auge et al., 2015), which is in accordance with our findings. Their extraradical mycelial network functions as an extension of the associated host root system, supporting the plant symbiosis partner among others with nutrients and water. In our study, the test plants responded under drought conditions to AM fungal colonization with a decrease in specific root surface area (Fig. 2). This effect might originate from an increase in root cortex area for the colonization of AM fungi leading to a greater root volume. AM fungi provided the test plants with water reducing the otherwise strong need for additional root growth under water scarcity (Eziz et al., 2017).

Contrary to our hypothesis, we found no modulating effects of AM fungi on polyester microfiber induced plant responses. This was unexpected, especially for aboveground biomass, where we detected clear individual AM fungal and microfiber signals. However, AM fungi only and AM fungi plus microfiber yielded similar aboveground biomass (Fig. 1), although we detected higher AM fungal root colonization under microfiber contamination compared to uncontaminated soil (Fig. 3). It is not clear why a positive biomass response to AM fungal root colonization, and positive effects of just microplastic fibers, did not result in greater increases in plant biomass when both treatments were applied. Root colonization captures AM fungal structures, and not functions; thus, it is possible that in the presence of microplastic fibers the plants derived no additional benefits from the AM symbiosis in terms of biomass. 
Table 2 Outcomes of the generalized least square models for percentage root colonization (PRC in $\%, n=40)$, organic matter loss (OML in $\%, n$ $=78$ ) and the investigated soil structure indices mean weight diameter (MWD in $\mathrm{mm}, n=80$ ) and water-stable aggregates (WSA in $\%, n=80)$ for the treatments $(\mathrm{AMF}=$ arbuscular mycorrhizal fungi, $\mathrm{MP}=$ microplastic, $\mathrm{D}=$ drought).

\begin{tabular}{|c|c|c|c|c|c|c|c|c|c|}
\hline \multirow[t]{2}{*}{ Treatments } & \multicolumn{3}{|c|}{ PRC } & \multicolumn{3}{|c|}{ OML } & \multicolumn{3}{|c|}{ MWD } \\
\hline & $\mathrm{df}$ & $F$ & $p$ & df & $F$ & $p$ & df & $F$ & $p$ \\
\hline AMF & & & & 1,70 & 10.78 & 0.0016 & 1,72 & 7.527 & 0.0077 \\
\hline MP & 1,36 & 2.93962 & 0.095 & 1,70 & 1.282 & 0.2613 & 1,72 & 5.275 & 0.0245 \\
\hline$D$ & 1,36 & 1.6576 & 0.2061 & 1,70 & 0.745 & 0.391 & 1,72 & 14.017 & 0.0004 \\
\hline AMF:MP & & & & 1,70 & 0.269 & 0.6058 & 1,72 & 0.286 & 0.5943 \\
\hline AMF:D & & & & 1,70 & 0.431 & 0.5138 & 1,72 & 0.6 & 0.441 \\
\hline$M P: D$ & 1,36 & 0.66364 & 0.4206 & 1,70 & 0.208 & 0.65 & 1,72 & 0.001 & 0.9821 \\
\hline AMF:MP:D & & & & 1,70 & 0.009 & 0.9233 & 1,72 & 1.565 & 0.215 \\
\hline
\end{tabular}

$p<0.05$ was considered significant and marked in bold. Degrees of freedom (df), $F$ - and $p$-value for each variable are presented.
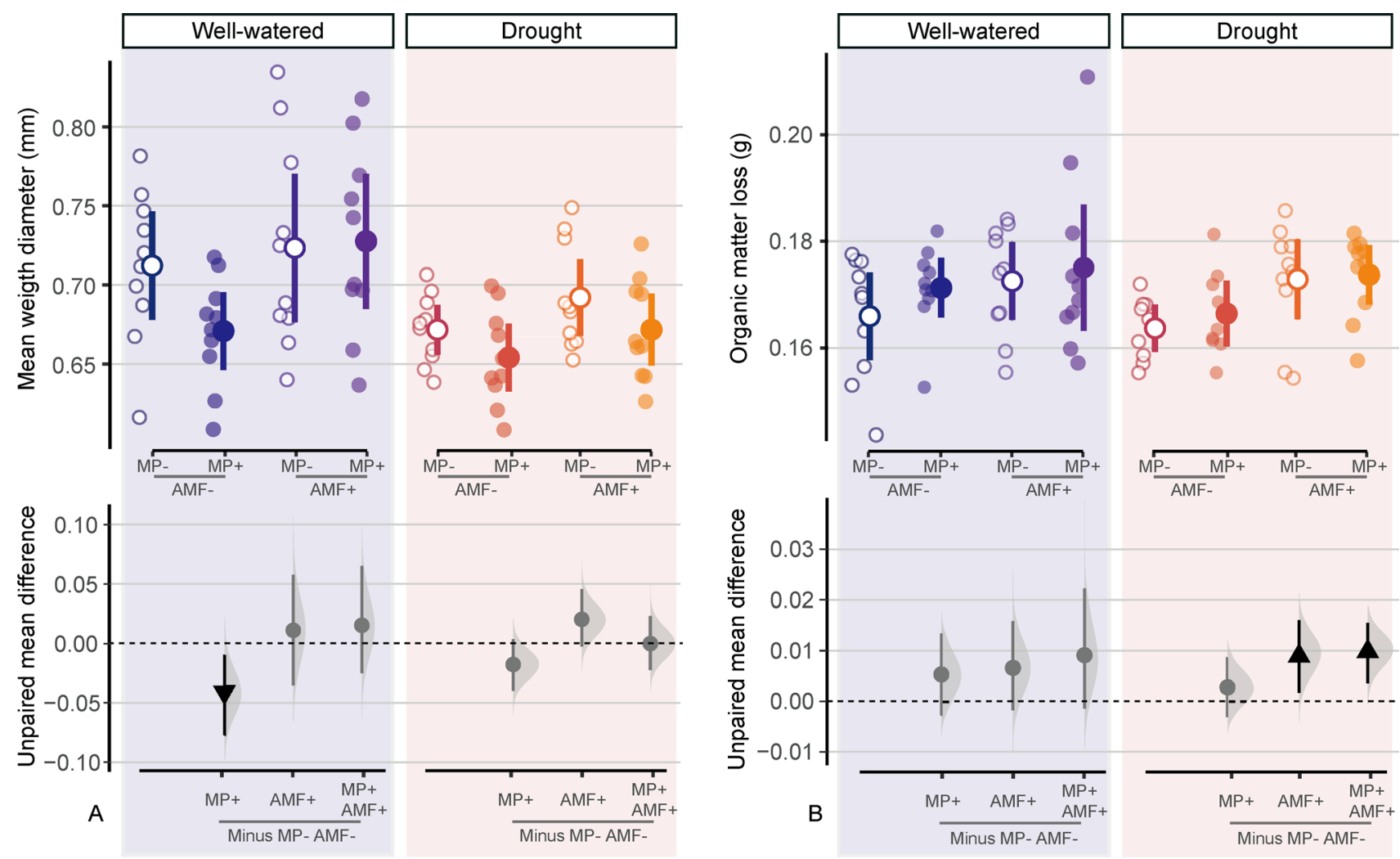

Fig. 4 Ecosystem process responses to application of microfibers, AM fungi and drought. Raw data distributions for mean weight diameter in $\mathrm{mm}(\mathrm{A})$ and organic matter loss in $\mathrm{g}(\mathrm{B})$ are presented as swarm plots (first row). Data distributions are aligned with corresponding mean and standard deviation ( $n=10$ for each group). Blueish colors represent well-watered and reddish drought conditions. Empty circles depict absence and filled circles presence of microfiber contamination. The multi-group estimation plots (second row) depict the unpaired mean differences of the microplastic- and AM fungal-only and microplastic-AM fungal combination under well-watered and drought scenario. Samples without AM fungi and microplastic were used as control group for well-watered and drought conditions, separately. Circles and triangles represent the effect size mean (unpaired mean; effect magnitude) and the vertical lines the corresponding confidence intervals (effect precision). The sampling error distribution is presented as a gray curve. Positive (arrow head up) or negative (arrow head down) effect sizes and corresponding Cls of treatment compared to control group are depicted in black while neutral effects (circle) are colored in gray; neutral effects occur when the Cls overlap the dashed zero line (line of no effect). Model outcomes of raw data analyses are presented in Table 2. 


\subsection{AM fungal response}

We found increased AM fungal root colonization, as an indicator for their abundance and an increase in arbuscules, as an indicator of potential AM fungal performance. Polyester microfibers have been shown to increase root growth, microbial activity (measured as fluorescein diacetate hydrolysis activity) and AM fungal colonization with hyphae, coils and arbuscules (Machado et al., 2019). We found quite substantial variation in AM fungal root colonization. This could be due to potential additives in the fiber product. Depending on the targeted purpose of fibers, they can contain a variety of additives such as softeners, flame retardants, UV protectors or antistatic agents, which can be persistent, bioaccumulative, and toxic compounds (Ezechias et al., 2014; Groh et al., 2019); however, producer information on these substances are limited. Upon release during degradation these can change the microbial community composition and possibly have adverse effects on microorganisms (Wang et al., 2019). Our knowledge of microplastic effects on soil microbes and especially AM fungi is rather limited and more research is needed to elucidate the consequences of microplastic soil contamination for mycorrhizal species.

In our study, we found no interacting effect of polyester microfibers and drought on AM fungal root colonization. Microfibers slightly increased root colonization, but drought only increased the variability of this effect (Fig. 3). The only clear fungal response to drought that we detected was the increased number of vesicles. The effects of abiotic stresses on AM fungi are not well understood. Drought has caused positive and negative effects on AM fungi abundance in the past (Sendek et al., 2019). As a result of reduced plant performance, drought can reduce AM fungal colonization rate and the abundance of arbuscules and vesicles. But drought can also induce the production of more resting structures and storage organs such as vesicles, in order to increase chances for survival under stressed conditions (Cabello, 1997). Therefore, we can assume that the AM fungi in our study were stressed by the water scarcity, which might have contributed to their reduced performance (see below for soil aggregation).

\subsection{Soil response}

In this study we focused on soil structure and decomposition to evaluate the soil response to microfiber soil contamination and potential mitigating effects of AM fungi under well-watered and drought scenarios. We found that the polyester microfibers reduced the average size of aggregates (MWD) under well-watered conditions but did not affect the overall stability of soil aggregates (WSA). Microfibers often have more pronounced effects on soil properties than other microplastic types (e.g., beads, films), but the results can vary substantially throughout the literature. There is a range of polyester microfiber-induced effects from positive to negative, but there are also reports of neutral impacts on the MWD (Machado et al., 2018b; Boots et al., 2019; Lehmann et al.,
2019; Zhang et al., 2019; Zhang and Zhang, 2020). The high variability in polyester microfiber-induced effects on soil structure is related to their diverse traits, e.g., the length (short or long), applied concentration (low or high), shape (linear or curly) or additives (e.g., softeners). For MWD, the fiber length is an important modulator. The available literature suggests that polyester microfibers $>3 \mathrm{~mm}$ increase (Zhang and Zhang, 2020) while microfibers $<3 \mathrm{~mm}$ decrease MWD (Machado et al., 2018b; Boots et al., 2019; Machado et al., 2019). In our study, we used short fiber fragments with an average length of $1.7 \mathrm{~mm}$, thus corroborating previous findings.

Biological factors like presence of plants (Hallett et al., 2009) or microbial species identity (Liang et al., 2019) also modulate soil responses. Plants can ameliorate negative microfiber effects on soil structure via their roots (Machado et al., 2018, 2019); physically by entanglement and chemically via root exudates gluing soil particles together (Hallett et al., 2009). In our study, we used a soil-plant-system with a diverse microbial community. The applied AM fungal strains had an overall positive effect on MWD (Table 2). In general, soil biota have positive effects on soil structure, mediated by a variety of biophysical, biochemical and biological mechanisms (Lehmann et al., 2017a; Lehmann et al., 2017b). Contrary to our hypothesis, AM fungi only improved the mean weight diameter of aggregates, but not the amount of water stable soil aggregates. Some of the soil aggregation mechanisms require the presence of organic matter or soil mineral particles such as clay. To promote the interaction between AM fungi and the host, we used a sandy soil, diluted with sand (50:50 w:w). Therefore, it is possible that the maximum of soil aggregation was reached because the coarse and thus unstable texture and diluted organic matter content did not allow for more soil aggregate stabilization by AM fungi.

The presence of microfibers did not reduce the positive AM fungal contributions to MWD (Fig. 4) under well-watered conditions. However, in the drought scenario, we detected a tendency that AM fungi were not as successful in compensating for the negative microfiber effect on MWD as under wellwatered conditions. Contrary to our expectations, this suggests that the microfiber induced reduction in soil bulk density and hence increasing water holding capacity (Machado et al., 2018b) do not protect the soil structure from detrimental drought effects. Additionally, the presence of AM fungi and improved plant aboveground and belowground growth could not compensate for the drought effect.

For decomposition, we found an AM fungal signal in the response of organic matter decomposition while polyester microfibers had no effect (Fig. 4, Table 2). AM fungi improved decomposition of high quality litter, such as leaves (e.g., Cheng et al., 2012). It was suggested that these fungi induce a shift in microbial community composition and stimulate decomposers that use labile carbon sources of the litter. The lack of a microfiber-induced effect on organic matter decomposition was unexpected. Zhang G S and Zhang F X (2020) reported similar findings for different polyester microfiber 
concentrations, thus corroborating our finding. However, changes in organic matter pools were detected for other microplastic polymers (Liu et al., 2017). Thus the type and polymer of plastic and soil parameters were suggested to be important modulators affecting the composition of the soil microbial community and changes in their metabolic activity (Machado et al., 2018b; Liang et al., 2019; Fei et al., 2020).

\section{Conclusions}

Our study adds additional support to the mounting evidence that microplastic fibers in soil can affect the plant-soil system by promoting plant growth, and favoring key root symbionts, AM fungi. Despite these effects, soil aggregation effects, which are positively influenced by plant roots and AM fungi, were still negative. This underlines the importance of negative effects of microplastics on the soil structure. Our study did not reveal an interaction of microplastic with the global change factor drought, but interactions are possible under different environmental or experimental settings and with other microplastic types and global change factors such as temperature increase, pesticide or heavy metal contamination.

\section{Acknowledgments}

MCR acknowledges funding from an ERC Advanced Grant (694368). EFL acknowledges funding from the Deutsche Forschungsgemeinschaft (LE 3859/1-1). JB acknowledges funding from the Deutsche Forschungsgemeinschaft (RI 1815/22-1).

\section{Author contributions}

A.L. designed the study and set up the experiment, with the help of L.F., E.F.L. and A.W.; A.L. performed analysis; L.F., provided experimental data; A.L., E.F.L., J.B. and M.C.R. wrote the manuscript; all authors contributed to the final version of the manuscript.

\section{Electronic supplementary material}

Supplementary material is available in the online version of this article at https://doi.org/10.1007/s42832-020-0060-4 and is accessible for authorized users.

\section{Open access}

This article is licensed under a Creative Commons Attribution 4.0 International License, which permits use, sharing, adaptation, distribution and reproduction in any medium or format, as long as you give appropriate credit to the original author(s) and the source, provide a link to the Creative Commons licence, and indicate if changes were made. The images or other third party material in this article are included in the article's Creative Commons licence, unless indicated otherwise in a credit line to the material. If material is not included in the article's Creative Commons licence and your intended use is not permitted by statutory regulation or exceeds the permitted use, you will need to obtain permission directly from the copyright holder. To view a copy of this licence, visit http://creativecommons.org/licenses/by/ $4.0 \%$.

\section{References}

Auge, R.M., Toler, H.D., Saxton, A.M., 2015. Arbuscular mycorrhizal symbiosis alters stomatal conductance of host plants more under drought than under amply watered conditions: a meta-analysis. Mycorrhiza 25, 13-24.

Bergmann, M., Mützel, S., Primpke, S., Tekman, M.B., Trachsel, J., Gerdts, G., 2019. White and wonderful? Microplastics prevail in snow from the Alps to the Arctic. Science Advances 5, eaax1157.

Boots, B., Russell, C.W., Green, D.S., 2019. Effects of microplastics in soil ecosystems: Above and below ground. Environmental Science \& Technology 53, 11496-11506.

Cabello, M.N., 1997. Hydrocarbon pollution: Its effect on native arbuscular mycorrhizal fungi (AMF). FEMS Microbiology Ecology 22, 233-236.

Cheng, L., Booker, F.L., Tu, C., Burkey, K.O., Zhou, L., Shew, H.D., Rufty, T.W., Hu, S., 2012. Arbuscular mycorrhizal fungi increase organic carbon decomposition under elevated $\mathrm{CO}_{2}$. Science 337 , 1084-1087.

Cole, M., Lindeque, P., Halsband, C., Galloway, T.S., 2011. Microplastics as contaminants in the marine environment: A review. Marine Pollution Bulletin 62, 2588-2597.

de Vries, F.T., Brown, C., Stevens, C.J., 2016. Grassland species root response to drought: consequences for soil carbon and nitrogen availability. Plant and Soil 409, 297-312.

Eerkes-Medrano, D., Thompson, R.C., Aldridge, D.C., 2015. Microplastics in freshwater systems: A review of the emerging threats, identification of knowledge gaps and prioritisation of research needs. Water Research 75, 63-82.

Ezechias, M., Covino, S., Cajthaml, T., 2014. Ecotoxicity and biodegradability of new brominated flame retardants: A review. Ecotoxicology and Environmental Safety 110, 153-167.

Eziz, A., Yan, Z., Tian, D., Han, W., Tang, Z., Fang, J., 2017. Drought effect on plant biomass allocation: A meta-analysis. Ecology and Evolution 7, 11002-11010.

Fei, Y., Huang, S., Zhang, H., Tong, Y., Wen, D., Xia, X., Wang, H., Luo, Y., Barceló, D., 2020. Response of soil enzyme activities and bacterial communities to the accumulation of microplastics in an acid cropped soil. Science of the Total Environment 707, 135634.

Fort, F., Cruz, P., Catrice, O., Delbrut, A., Luzarreta, M., Stroia, C., Jouany, C., 2015. Root functional trait syndromes and plasticity drive the ability of grassland Fabaceae to tolerate water and phosphorus shortage. Environmental and Experimental Botany 110, 62-72.

Groh, K.J., Backhaus, T., Carney-Almroth, B., Geueke, B., Inostroza, P.A., Lennquist, A., Leslie, H.A., Maffini, M., Slunge, D., Trasande, 
L., Warhurst, A.M., Muncke, J., 2019. Overview of known plastic packaging-associated chemicals and their hazards. Science of the Total Environment 651, 3253-3268.

Hakansson, I., Lipiec, J., 2000. A review of the usefulness of relative bulk density values in studies of soil structure and compaction. Soil \& Tillage Research 53, 71-85.

Hallett, P.D., Feeney, D.S., Bengough, A.G., Rillig, M.C., Scrimgeour, C.M., Young, I.M., 2009. Disentangling the impact of AM fungi versus roots on soil structure and water transport. Plant and Soil 314, 183-196.

Hartmann, N.B., Hüffer, T., Thompson, R.C., Hassellöv, M., Verschoor A., Daugaard, A.E., Rist, S., Karlsson, T., Brennholt, N., Cole, M., Herrling, M.P., Hess, M.C., Ivleva, N.P., Lusher, A.L., Wagner, M., 2019. Are we speaking the same language? Recommendations for a definition and categorization framework for plastic debris. Environmental Science \& Technology 53, 1039-1047.

Ho, J., Tumkaya, T., Aryal, S., Choi, H., Claridge-Chang, A., 2019. Moving beyond $P$ values: data analysis with estimation graphics. Nature Methods 16, 565-566.

Hoeksema, J.D., Chaudhary, V.B., Gehring, C.A., Johnson, N.C. Karst, J., Koide, R.T., Pringle, A., Zabinski, C., Bever, J.D., Moore, J.C., Wilson, G.W.T., Klironomos, J.N., Umbanhowar, J., 2010. A meta-analysis of context-dependency in plant response to inoculation with mycorrhizal fungi. Ecology Letters 13, 394- 407.

Jayne, B., Quigley, M., 2014. Influence of arbuscular mycorrhiza on growth and reproductive response of plants under water deficit: a meta-analysis. Mycorrhiza 24, 109-119.

Kemper, W.D., Rosenau, R.C., 1986. Aggregate Stability and Size Distribution, In: Lute, A., ed., Methods of Soil Analysis. Part IPhysical and Mineralogical Methods, 2 ed. SSSA, Madison, USA, pp. 425-443.

Keuskamp, J.A., Dingemans, B.J.J., Lehtinen, T., Sarneel, J.M., Hefting, M.M., 2013. Tea Bag Index: a novel approach to collect uniform decomposition data across ecosystems. Methods in Ecology and Evolution 4, 1070-1075.

Larson, J.E., Funk, J.L., 2016. Seedling root responses to soil moisture and the identification of a belowground trait spectrum across three growth forms. New Phytologist 210, 827-838.

Lehmann, A., Fitschen, K., Rillig, M.C., 2019. Abiotic and biotic factors influencing the effect of microplastic on soil aggregation. Soil Systems 3.

Lehmann, A., Leifheit, E., Rillig, M., 2017a. Mycorrhizas and Soil Aggregation, In: Johnson, N., Gehring, C., Jansa, J., eds., Mycorrhizal Mediation of Soil. Elsevier, pp. 241-262.

Lehmann, A., Leifheit, E.F., Gerdawischke, M., Rillig, M.C., 2020. Microplastics have shape- and polymer-dependent effects on soil processes. bioRxiv, 2020.2006.2002.130054.

Lehmann, A., Zheng, W., Rillig, M.C., 2017b. Soil biota contributions to soil aggregation. Nature Ecology \& Evolution 1, 1828-1835.

Liang, Y., Lehmann, A., Ballhausen, M.B., Muller, L., Rillig, M.C., 2019. Increasing temperature and microplastic fibers jointly influence soil aggregation by saprobic fungi. Frontiers in Microbiology 10, 2018-2018.

Liu, H., Yang, X., Liu, G., Liang, C., Xue, S., Chen, H., Ritsema, C.J., Geissen, V., 2017. Response of soil dissolved organic matter to microplastic addition in Chinese loess soil. Chemosphere 185,
907-917.

Machado, A.A.D., Kloas, W., Zarfl, C., Hempel, S., Rillig, M.C., 2018a. Microplastics as an emerging threat to terrestrial ecosystems. Global Change Biology 24, 1405-1416.

Machado, A.A.D., Lau, C.W., Kloas, W., Bergmann, J., Bachelier, J.B., Faltin, E., Becker, R., Görlich, A.S., Rillig, M.C., 2019. Microplastics can change soil properties and affect plant performance. Environmental Science \& Technology 53, 6044-6052.

Machado, A.A.D., Lau, C.W., Till, J., Kloas, W., Lehmann, A., Becker, R., Rillig, M.C., 2018b. Impacts of microplastics on the soil biophysical environment. Environmental Science \& Technology 52, 9656-9665.

Marvel, K., Cook, B.I., Bonfils, C.J.W., Durack, P.J., Smerdon, J.E., Williams, A.P., 2019. Twentieth-century hydroclimate changes consistent with human influence. Nature 569, 59-65.

Materechera, S., Alston, A., Kirby, J., Dexter, A., 1992. Influence of root diameter on the penetration of seminal roots into a compacted subsoil. Plant and Soil 144, 297-303.

McCormack, M.L., Adams, T.S., Smithwick, E.A.H., Eissenstat, D.M., 2012. Predicting fine root lifespan from plant functional traits in temperate trees. New Phytologist 195, 823-831.

McCormack, M.L., Dickie, I.A., Eissenstat, D.M., Fahey, T.J., Fernandez, C.W., Guo, D., Helmisaari, H.S., Hobbie, E.A., Iversen, C.M., Jackson, R.B., Leppälammi-Kujansuu, J., Norby, R.J., Phillips, R.P., Pregitzer, K.S., Pritchard, S.G., Rewald, B., Zadworny, M., 2015. Redefining fine roots improves understanding of below-ground contributions to terrestrial biosphere processes. New Phytologist 207, 505-518.

McGonigle, T.P., Miller, M.H., Evans, D.G., Fairchild, G.L., Swan, J.A., 1990. A new method which gives an objective measure of colonization of roots by vesicular - arbuscular mycorrhizal fungi. New Phytologist 115, 495-501.

Mintenig, S.M., Löder, M.G.J., Primpke, S., Gerdts, G., 2019. Low numbers of microplastics detected in drinking water from ground water sources. Science of the Total Environment 648, 631-635.

Ng, E.L., Huerta Lwanga, E., Eldridge, S.M., Johnston, P., Hu, H.W., Geissen, V., Chen, D., 2018. An overview of microplastic and nanoplastic pollution in agroecosystems. Science of the Total Environment 627, 1377-1388.

Niu, W., Guo, Q., Zhou, X., Helmers, M.J., 2012. Effect of aeration and soil water redistribution on the air permeability under subsurface drip irrigation. Soil Science Society of America Journal 76, 815820.

Nizzetto, L., Futter, M., Langaas, S., 2016. Are agricultural soils dumps for microplastics of urban origin? Environmental Science \& Technology 50, 10777-10779.

Pinheiro, J., Bates, D., DebRoy, S., Sarkar, D., Team, R.C., 2018. nlme: Linear and nonlinear mixed effects models, $R$ package version 3.1-137 ed.

Qi, Y., Yang, X., Pelaez, A.M., Huerta Lwanga, E., Beriot, N., Gertsen, H., Garbeva, P., Geissen, V., 2018. Macro- and micro-plastics in soil-plant system: Effects of plastic mulch film residues on wheat (Triticum aestivum) growth. Science of the Total Environment 645, 1048-1056.

R Development Core Team, 2014. R: A language and environment for statistical computing, version 3.4.1 ed. 
Rillig, M.C., 2012. Microplastic in terrestrial ecosystems and the soil? Environmental Science \& Technology 46, 6453-6454.

Rillig, M.C., 2018. Microplastic disguising as soil carbon storage. Environmental Science \& Technology 52, 6079-6080.

Rillig, M.C., Field, C.B., Allen, M.F., 1999. Soil biota responses to longterm atmospheric $\mathrm{CO}_{2}$ enrichment in two California annual grasslands. Oecologia 119, 572-577.

Rillig, M.C., Lehmann, A., 2020. Microplastic in terrestrial ecosystems. Science 368, 1430-1431.

Rillig, M.C., Lehmann, A., de Souza Machado, A.A., Yang, G., 2019a. Microplastic effects on plants. New Phytologist 223, 1066-1070.

Rillig, M.C., Lehmann, A., Ryo, M., Bergmann, J., 2019b. Shaping up: Toward considering the shape and form of pollutants. Environmental Science \& Technology 53, 7925-7926.

Rillig, M.C., Mardatin, N.F., Leifheit, E.F., Antunes, P.M., 2010. Mycelium of arbuscular mycorrhizal fungi increases soil water repellency and is sufficient to maintain water-stable soil aggregates. Soil Biology \& Biochemistry 42, 1189-1191.

Rillig, M.C., Ryo, M., Lehmann, A., Aguilar-Trigueros, C.A., Buchert, S., Wulf, A., Iwasaki, A., Roy, J., Yang, G., 2019c. The role of multiple global change factors in driving soil functions and microbial biodiversity. Science 366, 886-890.

Rose, L., 2017. Pitfalls in root trait calculations: How ignoring diameter heterogeneity can lead to overestimation of functional traits. Frontiers in Plant Science 8, 8.

Schussler, A., Walker, C., 2010. The Glomeromycot-A species list with new families and new genera. The Royal Botanic Garden Kew.

Sendek, A., Karakoç, C., Wagg, C., Domínguez-Begines, J., do Couto, G.M., van der Heijden, M.G.A., Naz, A.A., Lochner, A., Chatzinotas, A., Klotz, S., Gómez-Aparicio, L., Eisenhauer, N., 2019. Drought modulates interactions between arbuscular mycorrhizal fungal diversity and barley genotype diversity. Scientific
Reports 9, 9650

Smith, S.E., Facelli, E., Pope, S., Andrew Smith, F., 2010. Plant performance in stressful environments: interpreting new and established knowledge of the roles of arbuscular mycorrhizas. Plant and Soil 326, 3-20.

Thompson, R.C., Swan, S.H., Moore, C.J., vom Saal, F.S., 2009. Our plastic age. Philosophical transactions of the Royal Society of London. Series B, Biological Sciences 364, 1973-1976.

van den Berg, P., Huerta-Lwanga, E., Corradini, F., Geissen, V., 2020. Sewage sludge application as a vehicle for microplastics in eastern Spanish agricultural soils. Environmental Pollution 261, 114198.

van Kleunen, M., Brumer, A., Gutbrod, L., Zhang, Z., 2020. A microplastic used as infill material in artificial sport turfs reduces plant growth. Plants. People \& the Planet 2, 157-166.

Wagner, M., Scherer, C., Alvarez-Muñoz, D., Brennholt, N., Bourrain, X., Buchinger, S., Fries, E., Grosbois, C., Klasmeier, J., Marti, T., Rodriguez-Mozaz, S., Urbatzka, R., Vethaak, A.D., WintherNielsen, M., Reifferscheid, G., 2014. Microplastics in freshwater ecosystems: what we know and what we need to know. Environmental Sciences Europe 26, 12.

Wang, J., Liu, X., Li, Y., Powell, T., Wang, X., Wang, G., Zhang, P., 2019. Microplastics as contaminants in the soil environment: $A$ mini-review. Science of the Total Environment 691, 848-857.

Wickham, H., 2009. ggplot2: Elegant graphics for data analysis. Springer, New York.

Zhang, G.S., Zhang, F.X., 2020. Variations in aggregate-associated organic carbon and polyester microfibers resulting from polyester microfibers addition in a clayey soil. Environmental Pollution 258, 113716.

Zhang, G.S., Zhang, F.X., Li, X.T., 2019. Effects of polyester microfibers on soil physical properties: Perception from a field and a pot experiment. Science of the Total Environment 670, 1-7. 